\title{
Gabapentin as a Potential Treatment for Cough Syncope
}

\author{
Clara HK Wu, Keith Gunasekara, James H Hull MD PhD, Andras Bikov MD, \\ Adrian J Morris FRCP, and Omar S Usmani PhD FRCP
}

\section{Introduction}

Chronic cough, defined as cough lasting for $>8$ weeks, is one of the most common symptoms of medical importance, and the prevalence in the community is $9-33 \% .{ }^{1} \mathrm{~A}$ subgroup of patients suffer from the debilitating and distressing disorder of cough syncope, which is difficult to effectively manage and treat. The approach in clinic is to determine an underlying etiology for cough syncope and to treat the underlying cause with the hope that cough syncopal episodes will improve. In a situation in which cough syncope is idiopathic, current treatments are addressed directly at suppressing the sensory cough reflex. These include codeine, dextromethorphan, levodropropizine, moguisteine, local anesthetics (eg, lidocaine, mepivacaine) and low-dose morphine, yet the effects of these therapies are rather disappointing in alleviating this condition in patients. Indeed, there is a real unmet need for

\footnotetext{
Ms Wu and Mr Gunasekara are affiliated with Imperial College London, South Kensington Campus, London, United Kingdom. Drs Hull and Usmani are affiliated with Airway Diseases, National Heart and Lung Institute, Imperial College London and the Cough Clinic, Royal Brompton $\&$ Harefield NHS Foundation Trust, London, United Kingdom. Dr Bikov is affiliated with the Department of Pulmonology, Semmelweis University, Budapest, Hungary. Dr Morris is affiliated with William Harvey Hospital, Kent, United Kingdom.
}

$\mathrm{Ms} \mathrm{Wu}$ and Mr Gunasekara are co-first authors.

Dr Bikov is funded by a European Respiratory Society fellowship. Dr Usmani is funded by the UK National Institute for Health Research and has received travel grants from Chiesi, Takeda, and Aerocrine. He currently has research grants from Chiesi, AstraZeneca Pharmaceuticals, Takeda, and GlaxoSmithKline. Drs Usmani and Hull are supported by the National Institute for Health Research Respiratory Disease Biomedical Research Unit at the Royal Brompton \& Harefield NHS Foundation Trust and Imperial College London. Neither funding source was involved in writing this report or in the decision to submit. The other authors have disclosed no conflicts of interest.

Correspondence: Clara HK Wu, Imperial College London, South Kensington Campus, London SW7 2AZ, United Kingdom. E-mail: hkw09@ imperial.ac.uk.

DOI: $10.4187 /$ respcare. 03255 effective treatments in patients suffering from cough. ${ }^{2}$ It has been suggested that chronic cough is a neuropathic disorder, ${ }^{3}$ and gabapentin, a treatment for neuropathic pain, has recently shown evidence of efficacy. A recent randomized controlled trial demonstrated an improvement in cough-specific quality of life when gabapentin was used at high doses of up to $1,800 \mathrm{mg} .{ }^{4}$ This teaching case for health-care professionals describes the clinical assessment and medical management of a patient with cough syncope and highlights the effectiveness of low-dose gabapentin in controlling our patient's difficult-to-manage cough.

\section{Case Summary}

A 63-y-old man was referred to the Royal Brompton Hospital Cough Clinic with a chronic nonproductive cough of $8 \mathrm{y}$. His cough was socially distressing; in particular, he noticed his cough was triggered at mealtimes, which had led him to eat in isolation from his family. Of significance, he had experienced 2 sudden cough-associated syncopal episodes leading to emergency hospital visits for scalp suturing. These events had precipitated his referral to our specialist cough clinic. On assessment, he had no other respiratory symptoms and had never smoked. Medical review noted no symptoms of dyspepsia or postnasal drip, and he did not report a history of hay fever, asthma, eczema, or occupational exposure to chemical irritants. He had been treated for hypertension by his family practitioner with the angiotensin-converting enzyme inhibitor enalapril, which had subsequently been changed to an alternative antihypertensive drug, but without any resolution of his cough.

On medical examination, there were no cardiovascular, respiratory, neurological, or gastrointestinal abnormalities noted. His pulmonary investigations of spirometry, chest radiography, chest computed tomography, and endoscopic bronchoscopy were all normal. Bronchial hyper-reactivity testing with inhaled histamine was not significant, and overnight oximetry did not suggest obstructive sleep apnea. Neurological investigation undertaken with magnetic resonance imaging of the brain showed no structural abnormality, specifically no Arnold-Chiari malformation. 


\section{Gabapentin as a Potential Treatment for Cough Syncope}

Cardiovascular testing involving Holter monitoring for rhythm abnormalities was normal, and his echocardiogram did not identify any structural or functional dysfunction of the heart. Carotid artery ultrasound showed no arterial stenosis. Autonomic investigations, including the Valsalva maneuver, mental arithmetic testing, and cutaneous cold pressor testing, were performed to assess vagal and sympathetic responsiveness. Situational cardiovascular tilt testing detected an initial fall in blood pressure during coughing and then an overshoot after coughing.

Our patient received several treatment trials to try to manage his underlying cough and associated syncope. In relation to his mealtime-induced cough, he was treated with 3 months of a high-dose proton pump inhibitor $(40 \mathrm{mg}$ of lansoprazole daily) with little improvement in his cough. His cough symptom was also unresponsive to a variety of pulmonary and allergy treatments, including oral antihistamines (chlorpheniramine), inhaled high-dose long-acting $\beta$-agonist and corticosteroid combination treatment (formoterol and beclometasone dipropionate), and oral prednisolone. Codeine linctus, an opioid sometimes used to suppress a dry irritating cough in intractable situations, alleviated his acute cough episodes, but only for a few hours. Most significantly, his startling cough syncopal episodes did not resolve with any treatment. For this reason, we decided to treat our patient with low-dose gabapentin in light of recent data on the efficacy of gabapentin in chronic idiopathic cough. ${ }^{4}$ Remarkably, within a few weeks, his cough came under complete control with only $200 \mathrm{mg}$ of gabapentin daily. His quality of life dramatically improved such that he was able to dine with his family. He experienced no adverse effects, yet notably, when he omitted gabapentin for $3 \mathrm{~d}$, his cough reappeared. Most importantly, he experienced no cough-related syncopal episodes.

\section{Discussion}

The production of cough can result from voluntary or involuntary physiological responses. The involuntary (or reflex cough) response is triggered by cough receptors located in the airway bifurcation, larynx, and distal esophagus. ${ }^{5}$ Cough receptors are connected to afferent nerve fibers that originate from the vagus nerve and conduct signals to the nucleus tractus solitarius in the brainstem and then on to the central cough center, which transmits the signals into an efferent cough response. ${ }^{6}$ There are 3 types of cough receptors, defined by their conductive properties: (1) rapidly adapting receptors, (2) slowly adapting receptors, and (3) C-fibers.7,8 Rapidly adapting receptors are sensitive to cigarette smoke, acid and alkaline chemicals, and mechanical stimulation from chronic lung diseases. ${ }^{9,10}$ In contrast, C-fibers are stimulated by irritants such as bradykinin (a mediator released during inflammation) and capsaicin (a vanilloid extract of peppers). ${ }^{11}$ Tran-
Table 1. Causes of Cough Syncope

\begin{tabular}{l}
\hline \hline Cardiovascular \\
Carotid artery stenosis \\
Sinus arrest \\
Constrictive pericarditis \\
Neurological \\
Arnold-Chiari malformation \\
Posterior cranial fossa meningioma \\
Autonomic dysfunction \\
Respiratory \\
Obstructive sleep apnea \\
Smoking \\
\hline
\end{tabular}

sient receptor potential vanilloid-1 (TRPV-1) is a receptor for capsaicin that is found on rapidly adapting receptors and C-fibers. It also responds to heat, acid, bradykinin, arachidonic acid derivatives, and adenosine triphosphate. ${ }^{12}$ TRPV-1 has been shown to be increased in patients with chronic cough. ${ }^{13}$ Furthermore, patients with chronic cough have an increased cough sensitivity to inhaled capsaicin compared with normal subjects. ${ }^{14}$ Consequently, there is current interest in targeting the vanilloid receptor channels as a potential treatment for patients with chronic cough. ${ }^{15}$

Cough is a common respiratory symptom and is often the main reason for presentation to pulmonologists and respiratory physicians. ${ }^{16}$ Cough-associated syncope in particular is an alarming and debilitating condition for patients. It is a difficult-to-manage condition and is often associated with traumatic consequences for sufferers; in our patient, cough syncope led to scalp-suturing events. It is therefore important for health-care professionals to meticulously assess and investigate for an underlying etiological cause of cough syncope, paying particular attention to the cardiovascular, respiratory, and neurological systems with the approach that treating the underlying cause may alleviate these distressing episodes. Indeed, it is thought that cough may provoke syncope via impaired cardiac or autonomic blood pressure regulation. Therefore, the evaluation of cough syncope should consist of assessing sinus arrest, evaluating autonomic regulation, detecting carotid artery stenoses, and identifying abnormalities in the brain (in particular, structural defects in the cerebellum, such as Arnold-Chiari malformation, that can contribute to autonomic dysfunction) (Table 1). Some investigators have reported a potential pathophysiological mechanism for cough syncope in that a transient increase in intrathoracic pressure while coughing leads to reduced cerebral perfusion and subsequently to a brief loss of consciousness. ${ }^{17,18}$ Nevertheless, in some cases, the etiological cause of cough syncope remains unclear, so patients are managed with antitussive treatments to directly suppress the sensory cough reflex. 


\section{Gabapentin as a Potential Treatment for Cough Syncope}

In the clinical management of patients with chronic cough, a variety of antitussives are used, including opiates (codeine and morphine), histamine H1 receptor antagonists, dextromethorphan, levodropropizine, chlophedianol, and local anesthetics. The accepted standard antitussive, codeine, is one of the most widely prescribed medications for cough. However, multiple trials have demonstrated that it is poorly effective in controlling cough. ${ }^{19,20}$ The mechanisms by which histone $\mathrm{H} 1$ antagonists and dextromethorphan affect cough remain unclear. There have been no placebo-controlled trials for levodropropizine to date. ${ }^{2}$ Baclofen, a gamma-aminobutyric acid A receptor agonist, has been shown to inhibit capsaicin-induced cough in animals. ${ }^{21,22}$ However, human placebo-controlled trials are required to evaluate the efficacy of the drug. Indeed, there is an important placebo effect in patients with cough. ${ }^{23}$ Overall, the failure of current treatments is due to the complex components of the cough mechanism and a lack of consistent evidence of efficacy.

In this context, a recent randomized placebo-controlled trial involving 62 subjects demonstrated a significant improvement in cough-specific quality of life when gabapentin was used at high doses of up to $1,800 \mathrm{mg}$ daily for 3 months in comparison with a placebo. ${ }^{4}$ Gabapentin is a gamma-aminobutyric acid analog that acts on gammaaminobutyric acid $\mathrm{B}$ receptors and $\alpha_{2} \delta_{2}$ subunits of voltage-dependent calcium channels. ${ }^{24}$ Gamma-aminobutyric acid $\mathrm{B}$ receptors are expressed in the lungs and are involved in the prevention of bronchospasm, airway microvascular leakage, and cough, and $\alpha_{2} \delta_{2}$ subunits have been found to be expressed mainly in lung tissues in humans. ${ }^{25}$ Gabapentin is thought to bind to $\alpha_{2} \delta$ subunits in the central nervous system. Increased laryngeal hypersensitivity is a recognized finding in patients with chronic cough, and it has been proposed that gabapentin may act as an analgesic agent in inflammatory or neuropathic cough. ${ }^{26}$ Indeed, the effects of the drug on the peripheral nervous system are supported by its efficacy in sensory neuropathy-associated cough. ${ }^{27}$

An important consideration with all treatment interventions is adverse effects. In the randomized controlled trial of Ryan et al, ${ }^{4}$ high doses of gabapentin $(1,800 \mathrm{mg}) \mathrm{im}-$ proved cough-specific quality of life, but $31 \%$ of subjects experienced side effects that required dose reduction or treatment cessation. The main reported effects were nausea, fatigue, and dizziness. In contrast, lower doses of gabapentin have been utilized by previous investigators with good outcome. Mintz and Lee ${ }^{28}$ described the clinical outcome of gabapentin in 6 female subjects who were treated with lower doses of the medication ranging from 100 to $800 \mathrm{mg}$ twice daily. Similar to our patient in this teaching case, 5 of the 6 subjects in the study showed either complete resolution or substantial improvement in cough on low-dose treatment; however, the results from this study were not conclusive, as only a few female subjects were enrolled. Van de Kerkhove et al ${ }^{29}$ recently showed an improvement in cough symptoms with lower doses of gabapentin (600 mg twice daily). We were able to treat and completely control our patient's cough syncope with a very low dose (200 mg) of gabapentin after numerous standard cough treatments had been tried without any effect. The effects of gabapentin in improving his quality of life were clearly evident, and our report presents an important take-home message to practicing physicians to consider using smaller initial doses of gabapentin and then titrating up, particularly as efficacy may be achieved with a much lower dose compared with the reported clinical trials. This approach will also potentially minimize any side effects caused by the drug. In our clinic, our approach is to prescribe a starting dose of $100 \mathrm{mg}$ of gabapentin daily and then titrate up by $100 \mathrm{mg}$ daily every 2 weeks until the patient derives a subjective improvement in cough, at which point, the dose is maintained.

In summary, our teaching case describes cough syncope resulting from chronic intractable cough as a debilitating condition affecting our patient's quality of life. Our case illustrates that idiopathic chronic cough can be controlled at a significantly lower dose of gabapentin compared with recently published clinical trials, and this is an important message for health-care professionals. This observation should provide the basis for further academic research on investigating the mechanistic effects of the drug at lower doses. Indeed, the dose of gabapentin necessary to control chronic cough in the clinic may be quite different and possibly, as we have shown, lower compared with the established licensed indicated higher dose used for the control of neuropathic pain and epilepsy.

\section{Teaching Points}

- Cough syncope is a debilitating condition for which there is currently no effective treatment.

- Respiratory, cardiac, and neurological assessments are essential to ascertain an underlying etiology.

- The comprehensive evaluation of cough syncope should include investigation of autonomic function, vascular carotid artery disorders, structural and functional cardiac dysfunction, sleep disturbance, and anatomical brain abnormalities

- Low-dose gabapentin should be considered in managing such difficult-to-treat patients.

\section{ACKNOWLEDGMENTS}

We thank our patient for his consent to publish this case report. 


\section{Gabapentin as a Potential Treatment for Cough Syncope}

\section{REFERENCES}

1. Chung KF, Pavord ID. Prevalence, pathogenesis, and causes of chronic cough. Lancet 2008;371(9621):1364-1374.

2. Dicpinigaitis PV, Morice AH, Birring SS, McGarvey L, Smith JA, Canning BJ, Page CP. Antitussive drugs-past, present, and future. Pharmacol Rev 2014;66(2):468-512.

3. Chung KF, McGarvey L, Mazzone SB. Chronic cough as a neuropathic disorder. Lancet Respir Med 2013;1(5):414-422.

4. Ryan NM, Birring SS, Gibson PG. Gabapentin for refractory chronic cough: a randomised, double-blind, placebo-controlled trial. Lancet 2012;380(9853):1583-1589.

5. Widdicombe JG. Afferent receptors in the airways and cough. Respir Physiol 1998;114(1):5-15.

6. Shannon R, Baekey DM, Morris KF, Lindsey BG. Ventrolateral medullary respiratory network and a model of cough motor pattern generation. J Appl Physiol 1998;84(6):2020-2035.

7. Canning BJ, Mori N, Mazzone SB. Vagal afferent nerves regulating the cough reflex. Respir Physiol Neurobiol 2006;152(3):223-242.

8. Schelegle ES, Green JF. An overview of the anatomy and physiology of slowly adapting pulmonary stretch receptors. Respir Physiol 2001; 125(1-2):17-31.

9. Kou YR, Lee LY. Stimulation of rapidly adapting receptors in canine lungs by a single breath of cigarette smoke. J Appl Physiol 1990; 68(3):1203-1210.

10. Undem BJ, Carr MJ, Kollarik M. Physiology and plasticity of putative cough fibres in the guinea pig. Pulm Pharmacol Ther 2002; 15(3):193-198.

11. Undem BJ, Chuaychoo B, Lee MG, Weinreich D, Myers AC, Kollarik M. Subtypes of vagal afferent C-fibres in guinea-pig lungs. J Physiol 2004;556(Pt 3):905-917.

12. Caterina MJ, Julius D. The vanilloid receptor: a molecular gateway to the pain pathway. Annu Rev Neurosci 2001;24:487-517.

13. Groneberg DA, Niimi A, Dinh QT, Cosio B, Hew M, Fischer A, Chung KF. Increased expression of transient receptor potential vanilloid-1 in airway nerves of chronic cough. Am J Respir Crit Care Med 2004;170(12):1276-1280.

14. Choudry NB, Fuller RW. Sensitivity of the cough reflex in patients with chronic cough. Eur Respir J 1992;5(3):296-300.
15. Spina D, Page CP. Regulating cough through modulation of sensory nerve function in the airways. Pulm Pharmacol Ther 2013;26(5):486490.

16. Schappert SM. National Ambulatory Medical Care Survey: 1991 summary. Vital Health Stat 13 1994;(116):1-110.

17. Mattle HP, Nirkko AC, Baumgartner RW, Sturzenegger M. Transient cerebral circulatory arrest coincides with fainting in cough syncope. Neurology 1995;45(3 Pt 1):498-501.

18. Maznyczka A, Squire IB. Cough syncope-a diagnosis under pressure. Lancet 2010;376(9739):486.

19. Bolser DC, Davenport PW. Codeine and cough: an ineffective gold standard. Curr Opin Allergy Clin Immunol 2007;7(1):32-36.

20. Chang CC, Cheng AC, Chang AB. Over-the-counter (OTC) medications to reduce cough as an adjunct to antibiotics for acute pneumonia in children and adults. Cochrane Database Syst Rev 2007;(4): CD006088.

21. Bolser DC, Aziz SM, DeGennaro FC, Kreutner W, Egan RW, Siegel MI, Chapman RW. Antitussive effects of GABAB agonists in the cat and guinea-pig. Br J Pharmacol 1993;110(1):491-495.

22. Mutolo D, Bongianni F, Cinelli E, Pantaleo T. Depression of cough reflex by microinjections of antitussive agents into caudal ventral respiratory group of the rabbit. J Appl Physiol 2010;109(4):10021010.

23. Faruqi S, Molyneux ID, Fathi H, Wright C, Thompson R, Morice $\mathrm{AH}$. Chronic cough and esomeprazole: a double-blind placebo-controlled parallel study. Respirology 2011;16(7):1150-1156.

24. Cheng JK, Chiou LC. Mechanisms of the antinociceptive action of gabapentin. J Pharmacol Sci 2006;100(5):471-486.

25. Chapman RW, Hey JA, Rizzo CA, Bolser DC. GABAB receptors in the lung. Trends Pharmacol Sci 1993;14(1):26-29.

26. Ford PA, Barnes PJ, Usmani OS. Chronic cough and Holmes-Adie syndrome. Lancet 2007;369(9558):342.

27. Lee B, Woo P. Chronic cough as a sign of laryngeal sensory neuropathy: diagnosis and treatment. Ann Otol Rhinol Laryngol 2005; 114(4):253-257.

28. Mintz S, Lee JK. Gabapentin in the treatment of intractable idiopathic chronic cough: case reports. Am J Med 2006;119(5):e13-e15.

29. Van de Kerkhove C, Goeminne PC, Van Bleyenbergh P, Dupont LJ. A cohort description and analysis of the effect of gabapentin on idiopathic cough. Cough 2012;8:9. 